\title{
EVEKTIFITAS MEDIA PEMBELAJARAN DARING EDMODO DALAM PERKULIAHAN PENDIDIKAN AGAMA ISLAM PADA MASA PANDEMI COVID-19
}

\author{
Minten Ayu Larassati
}

Fakultas Keguruan dan IImu Pendidikan Universitas Cordova

Corresponding Autor email: mintenhijau@gmail.com

\begin{abstract}
Abstrak
Diterima:

Wabah Covid-19 sangat berpengaruh terhadap proses pembelajaran, karena perkuliahan

Bulan Juni 2020

tidak dapat dilaksanakan dalam bentuk kuliah tatap muka. Salah satu cara untuk dapat mencapai capaian pembelajaran adalah dengan menggunakan media pembelajaran system daring. Pembelajaran daring berfungsi sebagai penghubung antar dosen dan mahasiswa dengan jaringan internet yang dapat diakses kapan saja dan dimana saja. Media pembelajaran daring yang digunakan adalah Edmodo, sebuah platform pembelajaran yang

Diterbitkan :

Bulan Juli 2020 berbasis jejaring sosial. Tujuan dari penelitian ini adalah menganalisis keefektifan media edmodo pada perkuliahan PAI pada mahasiswa semseter 1, kelas mix di Universitas Teknologi Sumbawa. Jenis penelitan ini adalah kualitatif studi kasus, metode

Keyword:

Media Edmodo, PAI , Covid-19. pengumpulan data yang digunakan adalah dokumentasi, wawancara dan pengamatan. Hasil dari penelitian disimpulkan bahwa pandemi Covid-19 mengubah bentuk pembelajaran PAI menjadi daring, media yang di gunakan adalah edmodo. Edmodo dinilai efektif untuk melaksanakan proses pembelajaran karena, materi kuliah dapat diterima, dipelajari dan dilihat kembali, pengumpulan tugas lebih simple, mudah dan nilai dapat diterima langsung, menigkatkan kedisiplinan dan kekonsisten mahasiswa, mudah dan menyenagkan. Interaksi dan komunikasi selama belajar daring menjadi lebih mudah dan terarah dengan fitur-fitur yang di sediakan edmodo sehingga tujuan dan CPMK PAI dapat diperoleh dengan baik.
\end{abstract}

\section{PENDAHULUAN}

Munculnya pandemi Covid-19 (corona) berpengaruh pada sistem pembelajaran pendidikan agama Islam (PAI). System pembelajaran yang awalnya tatap muka di tengah semester berjalan beralih ke pembelajaran daring. Perkuliahan masa pandemic Covid-19 mau tidak mau menghasilkan system pembelajaran kombinasi antara tatap muka dan daring. Pembelajaran daring bertujuan memberikan layanan pembelajaran bermutu dalam jaringan (daring) yang bersifat massif dan terbuka untuk menjangkau peminat yang lebih banyak dan lebih luas. (Adhe Kartika, 2018). Dalam daring kombinasi pelaksanaan pembelajaran tidak dibatasi ruang dan waktu, yang tidak mewajibkan mahasiswa untuk selalu belajar di dalam ruang kelas dengan segala peraturan yang kaku.(Martika. Ni. Putu, 2018). Matakuliah PAI di Universitas Teknologi Sumbawa (UTS) dilaksanakan dalam kelas mahsiswa mix, dimana dalam salam satu kelas terdapat mahasiswa yang berlainan prodi dengan tujuan agar mahasiswa dapat saling berinteraksi dengan berbagai mahasiswa yang berlainan konsentrasi keilmuan secara massif. Karena dalam satu kelas terdapat mahasiswa yang memiliki latarbelakang progam studi dan bidang keilmuan yang berbeda, dosen terkendala dalam berkomunikasi dengan mahasiswa pada kelas yang di ampu. Sehingga, dosen pengampu mencari solusi agar dapat berkomunikasi dengan baik salah satunya adalah membuat grup chat setiap kelas yang diampu. Selama melaksanakan pembelajaran daring media yang digunakan adalah edmodo. Edmodo adalah platform media sosial yang mirip dengan facebook, dikembangkan khusus siswa dan guru dalam ruangan kelas virtual dapat berfungsi melaksanakan proses pembelajaran menjadi menarik, mudah digunakan. Media pembelajaran Edmodo digunakan lebih dari 29 juta pengguna di dunia (Eko Subiyantoro,2013). Berdasar ulasan tersebut maka tujuan dari penelitian ini adalah menganalisis tingkat efektifitas edmodo dalam melaksanakan pembelajaran daring selama masa pandemic Covid- 
19 menggunakan aplikasi edmodo dalam perkuliahan PAI.

\section{LANDASAN TEORI}

\section{Media Pembelajaran Daring}

Kata media berasal dari bahasa latin jamak dari medium yang berarti perantara atau pengantar, yaitu pengantar sumber pesan dengan penerima pesan. Media memiliki arti sempit dan luas, dalam artian sempit media adalah komponen bahan dan alat dalam system pembelajaran. Artian luas media adalah pemanfaat secara maksimal semua komponen dan sumber belajar. Menurut beberapa ahli, media pembelajaran adalah Alat, metode, dan teknik yang digunakan dalam rangka lebih mengefektifkan komunikasi dan interaksi antara guru dan siswa dalam proses pendidikan dan pengajaran (Oemar Hamalik, 1989). Media pembelajaran memiliki banyak definisi diantaranya menurut Association for Education and Communication Technology (AECT) mendefinisikan media yaitu segala bentuk yang dipergunakan untuk suatu proses penyaluran informasi, media pembelajaran merupakan teknologi pembawa pesan yang bisa dimanfaatkan untuk keperluan proses pembelajaran baik berupa sarana fisik, sarana komunikasi, alat perangsang agar terjadi proses pembelajaran dengan baik. (Chepi Riyana, 2009). Sedangkan yang dimaksud media pembelajaran daring adalah media pembelajaran yang memanfaatan jaringan internet dalam proses pembelajaran, karakterisktik pembelajaran daring berbeda dengan pembelajaran di kelas (luring), terdapat dua jenis komunikasi yaitu komunikasi sinkron dan asinkron. Beberapa saluran yang dipergunakan dalam komunikasi sinkron antara lain chat dan video conference ( Najib, Mada, \& Model, 2018). Fungsi media pembelajaran adalah pembawa pesan dari pendidik ke peserta didik guna mencapai capaian pembelajaran, secara spesifik media pembelajaran memiliki lima fungsi yakni sebagai penarik perharian peserta didik, memperjelas penyampaian pesan, mengatasi keterbatasan ruang, waktu dan biaya, menghindari adanya verbalisme dan salah tafsir, untuk megaktifkan dan mengefektifkan kegiatan belajar. (Kustiawan, Usep 2016).

\section{Edmodo}

Edmodo adalah media pembelajaran daring yang dapat dimanfaatkan untuk melakasanakan perkuliahan pada masa pandemic Covid-19. Edmodo merupakan situs jejaring sosial e-learning didesain khusus untuk pendidikan. Edmodo merupakan Social Learning Network (SLN) dengan elemen social mirip dengan Facebook yang fungsi utamanya adalah berbagi pakai (sharing) sumber belajar, melakukan interaksi dan komunikasi antara dosen dan mahasiswa serta antar mahasiswa, dan melakukan evaluasi belajar secara daring. Edmodo dikembangkan atas prinsip pengelolaan kelas berbasis kelompok dan sosial media. Edmodo sangat komprehensif sebagai sebuah course management system seperti Moodle, bedanya adalah aksesnya lebih cepat dan lebih mudah penggunaannya, dan menggunakan beberapa fitur yang fungsinya sama seperti course management system. Edmodo memiliki banyak model tugas yang akan dipilih oleh dosen, mulai dari penugasan dalam bentuk pengiriman file word, ppt, excel, video. Sampai pada ujian dalam bentuk pilihan ganda, mencocokan, esai, dan benar salah. Edmodo dalam American Association of School sebagai salah satu dari 25 situs web teratas pada tahun 2011 (Balasubraman dkk, 2014). Berikut adalah karekteristik dari edmodo (Sumber: SEAMOLEC, 2013 dalam Dharmawati, 2017)

Table 1: Karekteristik dari social media edmodo Edmodo

\begin{tabular}{|c|c|c|c|c|c|c|}
\hline \multirow{7}{*}{$\begin{array}{c}\text { Group User } \\
\text { Based on } \\
\text { Class//Subje } \\
\text { ct }\end{array}$} & \multicolumn{6}{|c|}{ Edmodo } \\
\hline & & \multirow{2}{*}{\multicolumn{2}{|c|}{$\frac{\text { Social Media Networki }}{\text { Evaluation }}$}} & \multicolumn{3}{|c|}{ nd Learning } \\
\hline & \multirow{5}{*}{$\begin{array}{c}\text { Communicatio } \\
\mathrm{n} \text { based on } \\
\text { Socil Media } \\
\text { Networking }\end{array}$} & & & Lea & Mater & / Modules \\
\hline & & \multirow{4}{*}{$\begin{array}{l}\text { Individual } \\
/ \text { Group } \\
\text { Assignme } \\
\mathrm{nt}\end{array}$} & $\begin{array}{l}\text { Quiz } \\
\end{array}$ & Tex & \multirow{4}{*}{$\begin{array}{l}\text { Vide } \\
\text { o }\end{array}$} & \multirow{4}{*}{$\begin{array}{l}\text { Web } \\
\text { Resource } \\
\text { s }\end{array}$} \\
\hline & & & 1 & \multirow[t]{3}{*}{$\mathrm{t}$} & & \\
\hline & & & Pool & & & \\
\hline & & & & & & \\
\hline
\end{tabular}

Edmodo sebagai sebuah platform pendidikan dijelaskan bahwasanya Edmodo is designed for educational purpose and there have been many teachers and students who use it, penjelasan tersebut menunjukkan orientasi penggunaan Edmodo khusus dirancang untuk tujuan pendidikan sehingga Edmodo telah dipakai oleh banyak guru dan siswa untuk menunjang kegiatan pembelajaran. Fitur-fitur yang terdapat pada Edmodo adalah ; (1) Polling, merupakan salah satu fitur yang hanya dapat digunakan oleh dosen, fitur ini digunakan untuk mengetahui tanggapan mahasiswa. (2) Gradebook, fitur ini mirip seperti catatan nilai mahasiswa. (3) Quiz, fitur ini hanya dapat dibuat oleh dosen Quiz digunakan untuk memberikan evaluasi onlinei kepada mahasiswa berupa pilihan ganda, isian singkat maupun soal uraian. (4) File and Links, fitur ini berfungsi untuk mengirimkan note dengan lampiran file dan link, biasanya data tersebut berekstensi .doc, .pptx, .xls, .pdf dan lain-lain. (5) Library, fitur ini berfungsi sebagai wadah untuk menampung berbagai file dosen dapat mengunggah bahan ajar seperti materi, presentasi, gambar, video, sumber referensi, dan lain-lain. (6) Assignment, fitur ini digunakan oleh dosen untuk memberikan tugas kepada mahasiswa secara online, Kelebihan dari fitur ini yaitu dilengkapi dengan waktu deadline, attach file yang memungkinkan mahasiswa mengirimkan tugas secara langsung. (7) Award Badge, berfungsi untuk memberikan suatu penghargaan kepada mahasiswa atau grup, (8) 
Parent Code, digunakan oleh orang tua mahasiswa untuk memantau aktifitas belajar, dari fitur-fitur ini edmodo merupakan pilihan yang sangat tepat untuk digunakan sebagai media pembelajaran online.

Mengenai pengguaan edmodo berdasar analisis wawancara mahaiswa mengalami kebingungan mengoprasikan ketika diawal, karena pada saat membuat akun mahasiswa mengalami hambatan ketika pengisian formulir pada user name, kegagalan terjadi diakibatkan user name yang diajukan memilki kesamaan dengan user name orang lain dan harus mengganti user name yang lebih unik lagi. Bentuk pembelajaran daring juga menjadi kendala diawal karena mahasiswa baru menyesuaikan diri dengan system pembelajaran yang menharuskan mahasiswa belajar mandiri dari jarak jauh. Untuk mengoprasionalkan system yang ada dalam edmodo mahasiswa menyatakan fiturfitur yang disediakan tidak ribet, mudah digunakan, dan seiring digunakannya mahasiswa merasa lebih senang dan nyaman menggunakan edmodo untuk perkulihan selama masa pandemic covid-19. Selain itu, aplikasi lebih mudah digunakan untuk membuka materi, mengerjakan dan mengumpulkan tugas sehingga perkuliahan secara daring menggunakan edmodo dinilai bagus sangat membantu proses perkuliahan.

Selama proses pembelajaran, dosen sebagai fasilitator mentrasfer ilmu kepada mahasiswa dengan terlebih dahulu mengunggah materi ajar, tugas dan quiz pada aplikasi Edmodo. Kemudian mahasiswa yang memiliki akun Edmodo dapat melakukan seluruh aktifitas belajar seperti mengetahui tugas, kuis, membuka materi ajar dan informasi lainnya. Media pembelajaran daring Edmodo menjadi efektif apabila terjadi kerja sama antara dosen dan mahasiswa untuk mensukseskannya, tanpa salah satu dari kedaunya keberadaan media pembelajaran daring Edmodo tidak akan berjalan lancar. Oleh dari itu, diperlukan komunikasi yang erat antar keduanya.

\section{Pendidikan Agama Islam}

Berlanjut pada Pendidikan Agama Islam diperguruan tinggi memiliki orientasi untuk mengetahui bagaimana cara beragama yang benar dan mempelajarinya sebagai sebuah pengetahuan. Pendidikan dalam bahasa arab disebut al tarbiyyah yang dapat diartikan sebagai education (pendidikan), ubpbringin (pembelajaran), teaching (pengajaran), instruction (perintah), pedagogy males (pembinaan kepribadian), beading (member makan), raising (of animals) (menumbuhkan) (Hans Wer,dalam J Milton Cowan 1974). Pendidikan Islam merupakan proses pengubahan tingkah laku yang bersifat sosial kepada individu dan masyarakat melalui aktivitas pengajaran yang sesuai dengan falsafah Islamiyah agar mampu menghadapi dan menyeimbangkan kehidupan. Al Abrasyi dalam Fadīlah (keutamaan) mendefinisikan secara sederhana pokok tujuan pendidikan Islam adalah pembentukan moral yang tinggi sehingga pendidikan budi pekerti adalah jiwa dari pendidikan Islam, dan mencapai suatu akhlak yang sempurna adalah tujuan sebenarnya dari pendidikan Islam (Abd. Rashmad Assegaf, 2013). Tujuan dari PAI adalah agar mahasiswa syarat dengan nilai-nilai Islamiyah, secara spesifik lagi tujuan pendidikan adalah untuk mengembangkan kekuatan akhlak, menimbulkan rasa cinta kepada agama, berpegang teguh pada ajarannya serta berperilaku yang sesuai dengan ajaran Islam. Tujuan dari pendidikan agama ini dapat terwujud dengan baik apabila perkuliahan berjalan secara efektif. Tingkat efektifitas perkuliahan PAI selama pandemi Covid-19 menggunakan media pembelajaran edmodo terjadi apabila proses perkuliahan berjalan dengan aktif, tujuan pembelajaran yang telah direncanakan dapat bersama-sama diwujudkan.

\section{METODE PENELITIAN}

Penelitian ini mengulas tentang efektifitas kelas daring menggunakan aplikasi edmodo pada matakuliah PAI semester 2 tahun ajaran 2019 di UTS. Penelitian ini bersifat kualitatif yaitu penelitian yang prosedurnya menghasilkan data deskriptif berupa kata-kata tertulis atau lisan dari orang-orang dan pelaku yang diamati (Lexy J. Moleong, 2008). Peneliti akan mengeksplorasi pengalaman dosen dan mahasiswa menggunakan Learning Management System edmodo, berfokus pada penggunaan aplikasi edmodo sebagai media pembelajaran daring dan proses keaktifan mahasiswa biak saat belajar materi, pengumpulan tugas, penilaian selama masa pandemic covid-19. Teknik pengumpulan data yang digunakan yaitu menggunakan metode dokumen, wawancara dan pengamatan. Metode dokumentasi yaitu metode mencari data mengenai hal-hal (variabel) yang berupa catatan, transkip, buku, surat kabar, majalah, notulen rapat, agenda, dan sebagainya (Suharsimi Arikunto , 1998). Dokumen merupakan sumber informasi yang bukan manusia (non human resources), metode ini digunakan untuk memperoleh data kerja mahasiswa dalam mengikuti materi perkuliahan dan mengumpulkan tugas. Data yang diperoleh selanjutnya dianalisis agar dapat diketahui efektifitas mahasiswa menggunakan media pembelajaran daring edmodo. Metode kedua yang digunakan adalah wawancara. Wawancara digunakan untuk mengetahui tanggapan mahasiswa menggunakan media pembelajaran daring edmodo dalam perkuliahan PAI selama masa pandemi covid- 
19 baik dari segi kenyamanan, kemudahan dan penilain tugas. Metode ketiga untuk mengumpulkan data adalah pengamatan, pengamatan yang di maksud adalah memperhatikan siklus belajar mahasiswa melalui edmodo. Dari pemilihan topik pembahasan, penelitian ini termasuk pada intrinsic case study karena dilakukan untuk memahami secara mendalam suatu kaus tertentu yaitu tentang bpenggunaan media pembelajaran daring aplikasi Edmodo pada matakuliah PAI. Obyek penelitian ini adalah Kelas PAI 6-PAI 10.

\section{HASIL DAN PEMBAHASAN \\ Penggunaan Media Pembelajaran Edmodo dalam Perkuliahan PAI}

Matakulia PAI di UTS memiliki beban 2 SKS yang dilaksanakan dalam kelas regular mix semester dua, perkuliahan memiliki 16 sesion pertemuan tatap muka dikelas selama satu semester. Pada rencana pembelajaran semester (RPS) yang telah di susun terdapat 14 materi dan 2 kali ujian; tengah semester dan akhir semester. Bahan kajian tersebut yakni; (1) Manusia Agama dan Islam, (2) Ke-iman-an dan Ketaqwa-an, (3) Ke-Tauhidan dan Kerosulan, (4) Sumber Hukum Islam, (5) Al Qur'an Sumber Hukum Islam Pertama, (6) Hadits Sumber Hukum Islam Ke-Dua, (7) Ijtihad Sumber Hukum Ke-tiga, (8) UTS, (9) Syariah dan Fikih, (10) Aqlaq/perilaku dalam konsep Islam, (11)Tasawuf kontenporer, (12) Ibadah Aspek ritual, (13)Etos kerja Islami, (14) Islam di era industry 4.0, (15) pajak persepektif islam dialkukan dengan belajar mandiri (16) UAS. Pada renca bentuk pembelajaran dilakukan dengan kuliah tatap muka dengan merode yang bervariasi yakni Presentasi, diskusi kelas; Small Group Discussion, Case Study. Drill Al Qur'an, Answer Gallery, dan belajar mandiri. Dikarenakan terjadi pandemic Covid-19 proses tatap muka dikelas dan metode perkuliahan mengalami perubahan, dari sesion pertama hingga ke delapan menggunakan bentuk kuliah. Sesion kesembilan hingga 16 dilaksanakan dalam bentuk kelas daring menggunakan edmodo, metode pembelajaran yang diterapkan adalah belajar mandiri, video, penugasan dan Quiz. Dari uraian ini dapat diakumulasi pembelajaran PAI dilaksanakan delapan kali tatap muka dan delapan kali perkuliahan daring, situasi ini menghasilkan model perkuliahan daring kominasi karena terdapat dua model perkuliahan tatap muka dan daring.

Selanjutnya akan dibahas mengenai rasionalisasi kepada mahasiswa bahwa perkuliahan PAI selama pandemi Covid-19 dilaksanakan dengan daring menggunakan edmodo sebagai media pembelajaran. Dosen sebagai fasilitator menjelaskan manfaat edmodo untuk mempermudah komunikasi dan interaksi pembelajaran, mengarahkan mahasiswa agar tetap semangat belajar walau tidak dalam bentuk kuliah tatap muka karena pandemi Covid-19. Penggunakan edmodo selama proses perkuliahan PAI memiliki tahapan sebagai berikut; (1) melakukan komunikasi dengan mahasiswa mengenai terjadinya wabah covid-19 dan pentingnya mencapai capaian pembelajaran dalam kondisi apapun. Sehingga terjadi kesepakatan menggunakan aplikasi edmodo. (2) Dosen membuat akun sebagai guru/dosen/pendidik agar mahasiswa dapat masuk dalam kelas yang telah dibuat. (3) Mahasiswa mengunduh aplikasi edmodo dan sing up atau daftar pada edmodo dan masuk dalam kelas berdasar kode yang telah dibuat. (4) Dosen mengunggahan materi dan tugas pada akun edmodo. (5) Mahasiswa belajar mandiri dengan mengunduh materi, berdiskusi baik dengan cara berkomentar atau pesan pribadidan dan mengunggah tuggas sesuai dateline. (6) Dosen melakukan pengamatan kinerja mahasiswa. (7) Dosen mengevaluasi media pembelajaran daring menggunakan edmodo selama perkuliahan PAI dengan wawancara menggunakan media whatshapp.

\section{Evektifitas Media Pembelajaran Edmodo}

Selama peroses perkuliahan terdapat 115 mahasiswa yang berhasil bergabung, jumlah ini melebihi dari mahasiswa yang terdaftar dalam siakad, hal ini terjadi karena ada mahasiswa yang membuat dobel akun karena disangka tidak berhasil membuat akun dan membuat ulang sehingga terdapat mahasiswa yang dobel nama, mahasiswa yang menempuh matakuliah PAI 6,7,8 dan 9 sejumlah 110 orang. Peneiliti mengarahkan untuk mengapus atau keluar dari kelas bagi mahasiswa yag dobel, agar diperoleh jumlah mahasiswa secara tepat. Perkuliahan dilaksanakan di edmodo diambil dengan rasionalisasi Edmodo cukup familier karena aplikasi ini sudah umum dipakai oleh mahasiswa sewaktu masih menempuh sekolah menegah sebagian mahasiswa perkulihan PAI familier menggunakan media edmodo.

Keefektifitas menggunakan media pembelajaran daring edmodo dalam perkuliahan PAI masa pandemic covid-19 merupakan gambaran tingkat keaktifan mahasiswa melaksanakan belajar mandiri dalam mempelajari materi, view video, berdiskusi melalui pesan, pengumpulan tugas, dan nilai yang diperoleh mahasiswa. Berdasarkan oleh dokumentasi tingkat efektifitas proses perkuliahan dapat dilihat dalam table berikut;

Tebel 2; Efektifitas media pembelajaran daring pada matakuliah Pendidikan Agama Islam menggunakan Edmodo. 


\begin{tabular}{|c|c|c|c|c|}
\hline $\begin{array}{l}\mathbf{N} \\
\mathbf{0}\end{array}$ & $\begin{array}{c}\text { Sesi } \\
\text { on }\end{array}$ & $\begin{array}{c}\text { Mater } \\
i\end{array}$ & Tugas & $\begin{array}{c}\text { Efektifita } \\
\mathrm{s}\end{array}$ \\
\hline 1 & 9 & $\begin{array}{l}\text { Syaria } \\
\text { h dan } \\
\text { Fikih }\end{array}$ & $\begin{array}{ll}\checkmark & \begin{array}{l}\text { Mahasiswa membuat akun di } \\
\text { edmodo sebagai siswa }\end{array} \\
\checkmark & \begin{array}{l}\text { Mempelajari slide presentasi } \\
\text { syariah dan fikih yang telah di }\end{array} \\
\text { unggah dalam google drive }\end{array}$ & $\begin{array}{l}\text { Sebayak } \\
114 \\
\text { mahasisw } \\
\text { a } \\
\text { mengump } \\
\text { ulkan }\end{array}$ \\
\hline 2 & 10 & $\begin{array}{l}\text { Akhla } \\
\text { k }\end{array}$ & $\begin{array}{ll}\text { Mempelajari slide presentasi } \\
\text { Akhlak yang telah di unggah } \\
\text { dalam google drive } \\
\checkmark & \text { Mengerjakan soal }\end{array}$ & $\begin{array}{l}\text { Sebayak } \\
112 \\
\text { mahasisw } \\
\text { a } \\
\text { mengump } \\
\text { ulkan }\end{array}$ \\
\hline 3 & 11 & $\begin{array}{l}\text { Tasaw } \\
\text { uf }\end{array}$ & $\begin{array}{ll}\checkmark \quad \text { Mempelajari slide presentasi } \\
\text { Tassawuf yang telah di unggah } \\
\text { dalam google drive } \\
\checkmark \quad \text { Mengerjakan soal }\end{array}$ & $\begin{array}{l}\text { Sebayak } \\
110 \\
\text { mahasisw } \\
\text { a } \\
\text { mengump } \\
\text { ulkan }\end{array}$ \\
\hline 4 & 12 & $\begin{array}{l}\text { Islam } \\
\text { di era } \\
\text { indust } \\
\text { ri } 4.0\end{array}$ & $\begin{array}{l}\text { Mempelajari slide presentasi } \\
\text { Islam di era industri } 4.0 \text { yang } \\
\text { telah di unggah dalam beranda } \\
\text { dosen di Edmodo } \\
\checkmark \quad \text { Mengerjakan soal }\end{array}$ & $\begin{array}{l}\text { Pai 6: } 33 \\
\text { Pai 7: } 40 \\
\text { Pai 8: } 11 \\
\text { Pai 9: } 14\end{array}$ \\
\hline 5 & 13 & $\begin{array}{l}\text { Etos } \\
\text { Kerja } \\
\text { Islami }\end{array}$ & $\begin{array}{ll}\checkmark & \text { Mempelajari slide presentasi } \\
\text { Etos Kerja Islami yang telah di } \\
\text { unggah dalam beranda dosen di } \\
\text { Edmodo } \\
\checkmark \quad \text { Mengerjakan soal }\end{array}$ & $\begin{array}{l}\text { Pai 6: } 30 \\
\text { Pai 7: } 40 \\
\text { Pai 8: } 14 \\
\text { Pai 9: } 16\end{array}$ \\
\hline 6 & 14 & $\begin{array}{l}\text { Ibada } \\
\text { h } \\
\text { Aspek } \\
\text { ritual }\end{array}$ & $\begin{array}{l}\text { Mempelajari vidio dengan } \\
\text { pembahasan Ibadah Aspek ritual } \\
\text { yang telah di uplud dalam } \\
\text { youtube dengan alamat } \\
\text { https://www.youtube.com/watch } \\
\frac{\text { ?v=uYe6qxnLUu8 }}{\text { Mengerjakan soal }}\end{array}$ & $\begin{array}{l}\text { View } 211 \\
\text { Pai 6: } 34 \\
\text { Pai 7: } 42 \\
\text { Pai 8: } 8 \\
\text { Pai 9: } 16\end{array}$ \\
\hline 7 & 15 & $\begin{array}{l}\text { Persia } \\
\text { pan } \\
\text { ujian } \\
\text { Akhir } \\
\text { Semes } \\
\text { ter }\end{array}$ & $\begin{array}{l}\text { Pembahasan kisi-kisi ujian dan } \\
\text { mekanismenya yang telah di uplud } \\
\text { dalam youtube dengan alamat } \\
\text { https://youtu.be/QNB23kLOipc } \\
\text { Pembahasan soal-soal ujian yang telah } \\
\text { di uplud dalam youtube dengan alamat } \\
\text { https://youtu.be/3l9R9OZkPMI }\end{array}$ & $\begin{array}{l}\text { Kisi-kisi } \\
\text { View } \\
\text { video } 159 \text {. } \\
\text { Pembahas } \\
\text { an soal } \\
\text { View } \\
\text { vidio172 }\end{array}$ \\
\hline 8 & 16 & $\begin{array}{l}\text { Ujian } \\
\text { Ahir } \\
\text { Semes } \\
\text { ter }\end{array}$ & $\begin{array}{l}\text { Dilaksanakan di dalam kelas edmodo } \\
\text { Dengan tipe soal multitipecois (pilihan } \\
\text { ganda) sejumlah } 20 \text { butir. } \\
\text { Soal di random seriap siswa } \\
\text { Waktu pengerjaan } 45 \text { menit }\end{array}$ & $\begin{array}{l}\text { Pai } 6: 38 \\
\text { PAI } 7: 41 \\
\text { PAI } 8: 14 \\
\text { PAI } 9: 16\end{array}$ \\
\hline
\end{tabular}

Dari table diatas dapat diuraikan bahwa mahasiswa mengalami fluktuasi ketika menggumpulkan tugas yakni sesion 9 sejumlah 114, sesion 10 sejumlah 112, sesion 11 sejumlah 110 , sesion 12 sejumlah 95 , sesion 13 sejumlah 100, sesion 14 sejumlah 100, sesion 15 sejumlah belajar mandiri dan mengamati video, Sesion 16 Ujian Akhir sebanyak 109. Jumlahnya tidak begitu signifikan, sehingga mahasiswa hampir 100\% megerjakan dan masuk pembelajaran daring PAI di Edmodo. Selain itu, video yang dibuat untuk mendukung perkuliahanpun diterima dengan baik oleh mahasiswa dengan hasil, materi ibadah aspek ritual 211, kisi-kisi ujian view 157 dan pembahasan soal ujian 172.

Terkait kuwalitas edmodo sebagai media pembelajaran daring pada matakuliah PAI berdasar analisis hasil wawancara adalah (1) Materi tertangkap (diterima) dengan biak karena materi dengan mudah dapat dilihat dipelajari kembali dengan membuka akun (2) Pengerjaan tugas menjadi lebih simple tanpa harus mencetak, menjilid terlebih daulu, pengumpulannya pun bisa langsung sampai kedosen. (3) Proses perkuliahan menjadi lebih efektif karena materi ajar disampaikan dalam bentuk PPT, vidio Youtube yang dapat dilihat di akun masing-masing mahasiswa (4) Mahasiswa menjadi konsisten mengerjakan tugas karena pengerjaanya diberikan masa tenggang, jika lewat dari batas waktu yang ditentukan maka tidak akan mendapatkan nilai fitur ini dapat memberi traidmen mengerjakan tugas awal waktu dan menggumpulkan tepat waktu (5) Hasil tugas dan ujian dapat lansung diterima, sehingga tanpa butuh waktu yang lama kemampuan mahasiswa dapat diukur (6) Belajar lebih mudah dan menyenagkan. Mudah karena fitur edmodo cenderung tidak susah di gunakan, menyenagkan karena belajar tidak dibatasi oleh ruang, waktu dan dapat di kerjakan dimanapun dan kapanpun (8) Penerapan kelas mix menjadikan saling mengenal mahasiswa lintas jurusan, sehingga pertemanan semakin banyak tidak terbatas pada mahasiswa sesama program studi saja. Analisis hasil wawancara ini dapat ditarik kesimpulan bahwa media pembelajaran daring menggunakan edmodo dinilai efektif untuk melaksanakan proses pembelajaran daring selama pandemi Covid-19.

\section{PENUTUP \\ Kesimpulan}

Berdasarkan hasil penelitian yang sudah dilakukan, maka dapat disimpulkan bahwa;

Pandemi Covid-19 mengubah rencana pembelajaran yang disusun dimana sebelumnya bentuk pembelajaran bentuk kuliah tatap muka menjadi pembelajaran daring metode belajar mandiri, penugasan dan quiz. Media pembelajaran yang digunakan selama proses perkuliahan adalah edmodo. Pengoprasionalan edmodo releratif mudah dengan fitur-fitur tidak ribet, mudah digunakan, dan seiring digunakannya menjadikan pembelajaran lebih menyenagkan sehingga mahasiswa nyaman selama belajar model daring dirumah. Keefektifan menggunakan media pembelajaran edmodo pada masa pandemi Covid-19 berdasar analisis data dokumentasi adalah mahasiswa sebagian besar mengumpulkan tugas tepat waktu, mengamati video dan mengunduh materi perkuliahan setiap sesion. Jumlah mahasiswa mengalami flugtuasi dan tidak signifikan, sehingga rata-rata mahasiswa 96\% masuk dan megerjakan perkuliahan PAI di Edmodo. Kualitas pembelajaran menggunakan media edmodo pada matakuliah PAI dinilai menjadi lebih efektif karena materi diterima dan dapat dipelajari ulang, pengerjaan dan pembagian tugas menjadi lebih simple, materi yang disampaikan lewat ppt dan vidio, tugas konsisten dikerjakan karena memiliki masa tenggang pengerjaan, Hasil tugas dan ujian dapat lansung dilihat. Belajar lebih mudah dan menyenagkan, dengan kelas mix menjadikan saling mengenal mahasiswa lintas jurusan. Berdasar wawancara dapat disimpulkan perkuliahan PAI lebih efektif, mudah, menyenagkan, dan 
menigkatkan kedisiplinan mahasiswa selama belajar mandiri menggunaka edmodo. Interaksi dan komunikasi selama proses perkuliahan dapat terarah sehingga tujuan dan campaian pembelajaran mata kuliah dapat bersama-sama diperoleh dengan baik. Kebingungan mengunakan media pembelajaran edmodo terjadi pada tahap awal persiapan pada pembuatan akun dan penyesuaian diri untuk melaksanakan perkuliahan secara daring dengan media edmodo.

\section{REFERENSI}

Abd. Rashmad Assegaf. Aliran-Aliran Pendidikan Islam Hadrah Keilmuan Tokoh Klasik Sampai Moderen Jakarta: Grafindo Persada, 2013.

Adhe. Kartika. R. Model Pembelajaran Daring Matakuliah Kajian PAUD di Jurusan PG PAUD Fakultas Ilmu Pendidikan Universitas Negeri Surabaya. Journal of early childhood care \& education, 2018:vol. 1 No. 1

Al Jamali, Muhammad Fadlil,. Falsafah Pendidikan dalam Al Qur'an. Surabaya: Bina Ilmu. 1986

Arikunto Suharsimi, 1998. Prosedur Penelitian: Suatu Pendekatan Praktek. Jakarta : Rineka Cipta.

Balasubraman, K., Jaykumar, V., dan L.N. Fukey. 2014. A Study on "Student Preference Towards The Use of Edmodo as a Learning Platform to Create Responsible Learning Environment. Procedia - Social and Behavioral Science. 5th Asia Euro Conference 2014: 416-422

Chepi Riyana M.Pd, Dra. Rudi Susilana Msi. Media Pembelajaran : Hakikat, Pengembangan, Pemanfaatan dan Penilaian. Bandung: CV. Wacana Prima. 2009

Dharmawati. Penggunaan Media e-Learning Berbasis Edmodo dalam Pembelajaran English for Business. Jurnal Sistem Informasi 1. 2017.

Eko Subiyantoro dkk., Simulasi Digital Jilid 1, Jakarta: Dirjen Peningkatan Mutu Pendidik\&Tenaga Kependidikan, 2013.

Hans Wer, Mu'jam Al Lughah Al Arabiyah al Mu'asharah (A Dictionary of modern written Arabic. (ED), J Milton Cowan, Beirut: Linerarie Du Liban \& London: Mocdonald \& Evans LTD,1974.

Kustiawan, Usep. Pengembangan Media Pembelajaran Anak Usia Dini. Gunung Samudera:2016.

Lexy J. Moleong, Metode Penelitian Kualtatif, Edisi Revisi. Bandunng: Rasindo Karya, 2008.
Martika. Ni. Putu. Penerapan Program Guru Pembelajar Moda Daring Kombinasi Terhadap Peningkatan Hasil Uji Kompetensi Guru Bahasa Indonesia Tingkat SMA Di Kabupaten Gianyar. eJournal Jurusan Pendidikan Bahasa dan Sastra Indonesia, 2018: Vol. 7 No.2.

Najib, W., Mada, U. G., \& Model, E. Analisis Penerapan Pembelajaran Daring Pada Mata Kuliah Jaringan Komputer dengan Metode Massive Open Online Course ( MOOC ). Pemaparan: November 2017.

Oemar Hamalik, Media Pendidikan. Bandung : Citra Aditya, 1989.

Suharsimi Arikunto, Prosedur Penelitian Suatu Pendekatan Praktik. Jakarta: Rineka Cipta, 1998. 